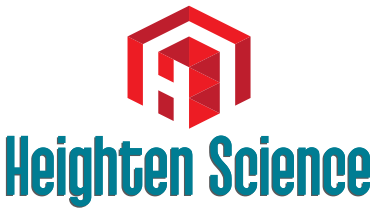

P U B L I C A T I O N S Corporation

Research Article

\section{Cytogenetic and clinical features of longlivers with osteoarthritis from Precarpathian region (West Ukraine) for 1998-2014yy}

\author{
Kozovyy $\mathbf{R}^{1 *}$, Kovalchuk $\mathrm{L}^{2}$ and Kitsera $\mathbf{N}^{3}$ \\ ${ }^{1}$ Assistant Professor, Department of Medical Biology and Medical Genetics, Ivano-Frankivsk \\ National Medical University, Ukraine \\ 2Professor, Department of Medical Biology and Medical Genetics, Ivano-Frankivsk National \\ Medical University, Ukraine \\ ${ }^{3}$ Department of Birth Defects and Hereditary Pathology, Institute of Hereditary Pathology, \\ National Academy of Medical Sciences of Ukraine, Lviv, Ukraine
}

\section{Abstract}

*Address for Correspondence: Kozovyy Ruslan, Assistant Professor, Department of Medical Biology and Medical Genetics, IvanoFrankivsk National Medical University, IvanoFrankivsk, 76000, Halytska str. 2, Ukraine, Tel. +380973342609; Email: ruslan_kozoviy@ukr.net; nkitsera@gmail.com

Submitted: 26 March 2019

Approved: 02 May 2019

Published: 03 May 2019

Copyright: (C) 2019 Kozovyy R, et al. This is an open access article distributed under the Creative Commons Attribution License, which permits unrestricted use, distribution, and reproduction in any medium, provided the original work is properly cited

Keywords: Longlivers; Osteoarthritis; Ukraine

Check for updates
Osteoarthritis is the most common form of arthritis, affecting millions of people worldwide.

Aim of our study was to assess the clinical and the cytogenetic characteristics in longlivers with osteoarthritis from Precarpathian region (Ukraine).

Methods: Cytogenetic, Clinical

Results: All of the subjects were separated into three groups: I group - 146 longlivers patients who had hypertension and osteoarthritis (OA); II group - 93 longlivers patients only with OA. The control (third) group included 130 patients aged 90-102 years without osteoarthritis and hypertension in anamnesis. In the age group more than 95 years, men and women of both groups were significant difference $(p<0,05)$ to be compared with control.

Cytogenetic characteristics of the long-livers with on osteoarthritis showed that most there is a tendency for a higher frequency of chromosomal aberrations in male long-livers and tere are significant difference among control $(p<0,05)$. The number of chromosomes associated in a single cell was significantly higher $(p<0,05)$ in both groups compared to control.

Conclusion: The importance of this study resides, to the best of our knowledge, in the fact that the largest group of patients in Ukraine was analyzed and assessed.

\section{Introduction}

Osteoarthritis is the most common form of arthritis, affecting millions of people worldwide. It occurs when the protective cartilage on the ends of your bones wears down over time. Osteoarthritis is a topic covered in the ICD-10-CM (M15-19). The pathogenesis of $\mathrm{OA}$ is not fully understood but some of the factors which contribute towards the development of $\mathrm{OA}$ include genetics, obesity, joint injury and occupational factors $[5,7,14]$.

The most common symptoms of osteoarthritis are stiffness, particularly first thing in the morning or after resting, and pain. Some people also experience swelling, tenderness and a grating or crackling sound when moving the affected joints $[1,5,16]$.

Globally, as of 2010, approximately 250 million people had osteoarthritis of the knee (3.6\% of the population). Hip osteoarthritis affects about $0.85 \%$ of the population 
[2,13]. As of 2012, osteoarthritis affected 52.5 million people in the United States, approximately $50 \%$ of whom were 65 years or older [13]. It is estimated that $80 \%$ of the population have radiographic evidence of osteoarthritis by age 65 , although only $60 \%$ of those will have symptoms $[5,13,17]$.

In Ukrainian population, the prevalence of symptomatic $\mathrm{OA}$ was $34.2 \%$, presenting a difference in sex and region (higher in rural areas than in urban areas) [4,11]. In 1997, 42.2 thousand cases of osteoarthritis were diagnosed in Precarpathian region, and in 2014 it was 53.2 thousand [9].

The proportion of older people is constantly increasing in most industrialized countries. For instance, while $21 \%$ of the German population were 65 years or older in 2013 , it is expected that at least every third person will be older than 65 years by 2060 and there will be twice as many people aged 70 or older as there are births in Germany [10]. Physical activity reduces joint pain in older adults with osteoarthritis, and helps them to maintain or improve functioning $[5,10,18]$.

Zengini E et al. performed a genome-wide association study for osteoarthritis using data across 16.5 million variants from the UK Biobank resource. Following replication and meta-analysis in up to 30,727 cases and 297,191 controls, they reported 9 new osteoarthritis loci, in all of which the most likely causal variant is non-coding [19].

The main objective of the EPOSA study is to investigate the personal and societal burden of OA and its determinants in 669 older adults (65-85 years) in five European countries (Germany, the Netherlands, Spain, Sweden, and the United Kingdom). [15].

Because osteoarthritis is a leading cause of disability worldwide and carries a substantial public health and health economics burden, that aim of our study was to assess the clinical and the cytogenetic characteristics in longlivers with osteoarthritis from Precarpathian region (Ukraine).

\section{Materials and Methods}

This retrospective study evaluated 369 longlivers from Precarpathian region (West Ukraine) who were diagnosed and followed-up at the underwent karyotyping over a period of 16 years (1998-2014) in the Genetic Laboratory of the State Medical University "Ivano-Frankivsk National Medical University", Ukraine.

Our study were conducted in compliance with the main provisions of the GCP (1996), the Council of Europe Convention on Human Rights and Biomedicine of 04.04.1997, the Helsinki Declaration, Orders of the Ministry of Health of Ukraine.

All of the subjects were separated into three groups: I group - 146 longlivers patients who had hypertension and osteoarthritis (OA); II group - 93 longlivers patients only with OA. The control (third) group included 130 patients aged 90-102 years without osteoarthritis and hypertension in anamnesis.

The exclusion criteria included the patients with birth defects or hereditary pathology, cancer, somatic pathology grade III or more.

The examination was carried out on the basis of the therapeutic department №1 and №2, the rheumatologic department of the Central City Clinical Hospital, the department of arterial hypertension of the Regional Clinical Cardiology Clinic in IvanoFrankivsk and the rheumatologic department of the Ivano-Frankivsk Regional Clinical Hospital, and further observation was carried out outpatient.

At baseline we collected data in person with a socio-demographic questionnaire (e.g., age, socioeconomic status, education). All patients were interviewed in a clinical center, using a standardized questionnaire and a clinical exam. A medical health history 
questionnaire to ascertain information about major comorbidities (e.g., diabetes, hypertension, cardiovascular disease) was administered.

The osteoarthritis confirmed by reference to the medical records of the orthopaedic surgeon and the original radiographs when possible. Osteoarthritis diagnosed according to the criteria of the American College Rheumatologists and European Criteria (ESCEO, 2014) based on clinical and radiological changes and consultation of the rheumatologist in older patients.

To study the peculiarities of karyotype in OA, a sample of 188 longlivers was created taking into account their desire and health at the time of blood collection.

For cytogenetic analysis, peripheral blood was used as biological material. Two milliliters peripheral blood was drawn in a sterilized syringe under complete aseptic conditions. Rest of the blood was transferred in heparinized vial. Add $5 \mathrm{ml}$ of either PBMAX Karyotyping Medium of KARYOMAX to each sterile T-25 flask to be set up for the assay. Add $1 \mathrm{ml}$ blood to each tube. Incubate flask in $\mathrm{CO} 2$ incubator for 48-68 hours with caps loose. Add $0.1 \mu \mathrm{g} / \mathrm{ml}$ COLCEMID to each flask for a 30 minute incubation. After 15 minutes, transfer flask contents to a $15 \mathrm{ml}$ centrifuge tube and spin down at $1200 \mathrm{rpm}$ for 5 minutes. Remove supernatant and re-suspend pellet. Add $10 \mathrm{ml}$ of $0.075 \mathrm{M} \mathrm{KCI}$ to pellet and gently mix. Allow to sit at room temperature for 15 minutes Add $0.5 \mathrm{ml}$ of fixative (three parts absolute methanol to none part glacial acetic acid). Gently mix with pipette. Centrifuge for 5 minutes at $1200 \mathrm{rpm}$. Aspirate off supernatant. Add $10 \mathrm{ml}$ of fixative, mix and let sit at room temperature for 15 minutes. Repeat centrifugation step. Add $5 \mathrm{ml}$ of fixative, mix, and let sit 10 minutes at room temperature. Centrifuge and aspirate off supernatant. Add $5 \mathrm{ml}$ of fixative and incubate for 10 minutes at $4^{\circ} \mathrm{C}$. The cytogenetic karyotype was analyzed on lymphocytes cultured from human peripheral blood. A minimum of 30 metaphases was accepted and analyzed through GTG banding with 450-550 band resolutions observed on microscope (Axiostar plus, Carl Zeiss, Germany) [6,8]. Cytogenetic analyses were performed on phytohaemagglutininstimulated lymphocytes according to standard protocol [6,12].

Determined the immunocytogenetic status of the organism, the frequency of association of acrocentric chromosomes, structural and quantitative chromosomal aberrations according to the criteria [3]. The evaluation of AAC included the absence of an overlap of acrocentric chromosomes, the orientation of short shoulders, and the distance between the acrocentrics without satellite, which did not exceed the size of the long shoulder of the chromosome from group $\mathrm{G}$.

Calculated associative index, as the ratio of the number of cells with associations to the total number of analyzed cells, in a $100 \%$ calculation. Also the average number of $\mathrm{AAC}$ in a single cell and the average number of chromosomes in one association were determined [20].

We considered the following data for each patient: age at diagnosis of OA, age at the time of the study, medical history and karyotype. Clinical history was recorded too.

\section{Results}

In Precarpathian region (West Ukraine) according to the Statistical Office on January, 2015 population [9] was 1,382,600 persons, including 727,800 women (52.6\%).

We studied the cohort of patients came from 14 districts of Ivano-Frankivsk region and Ivano-Frankivsk town (1998-2014 yy). Our cohort included 369 long-livers aged 90-102 years - 239 longlivers with $\mathrm{OA}$ and 130 longlivers without this pathology. We observed significantly $(\mathrm{p}<0,05)$ more likely $244(66,1 \%)$ female than $125(33,9 \%)$ men and aged $90-102$ years. 
Among 369 patients, 298 long-lived people aged $90-95(80,8 \%), 67$ people $(18,2 \%)$ over 95 years old, 4 long-lived people $(1,1 \%)$ were more than 100 years old (Table 1). In control and group II we have not seen any woman over 100 years of age. We observed only two women aged 101 and 102 years in group I, who had osteoarthritis and hypertension. Man aged 102 years only with osteoarthritis was the oldest in our cohort.

Among 146 longlivers (group I) with hypertension and osteoarthritis the median of age was $95 \pm 4.8$ years, II group - 93 longlivers patients only with OA (median of $94 \pm 4.1$ ). The mean age of the patients in control group was $93 \pm 3.9$ years. Although no significant difference was found with regard to the age of the groups $(p>0.05)$ under investigation, however, the greatest age at the time of examination was in patients with $\mathrm{OA}$ and hypertension compared with the control group. This explained by the fact that patients of group I had health problems and more often turned to doctors than longlivers without any complaints.

In the age group of 90-95 years, prevailed women from the control group - 80 $(92,0 \%)$ and men from the group II (only with $0 A)-24(80,0 \%)$ however, no significant difference was found $(\mathrm{p}>0,05)$.

In the age group more than 95 years, men and women of both groups were significant difference $(\mathrm{p}<0,05)$ to be compared with control. More than 95 years old, women $-18(28,6 \%)$ from the group II (only with OA) most often also met $(\mathrm{p}<0,05)$. Among men in the age group over 95 years the least diagnosed OA in group II (only with OA) -5 (16,7\%), among women - in group I (osteoarthritis and hypertension) -23 $(24,5 \%)$.

Three long-livers (two woman and one man) of the age over 100 had a combination of osteoarthritis and hypertension.

At the time of the survey in two groups (I and II) duration of OA was from 15 to 38 years, on average $(29,4 \pm 8,1)$ years, in group I duration of HD was from 10 to 35 years, on average $(17,2 \pm 6,9)$ years.

Studying the peculiarity of process of osteoarthritis at the Precarpathian longlivers it has been found out, that the beginning of manifestation of diseases at them starts mostly at the age of 75-89 years old, which for long time had been preserving them active physical state. One man from group I aged 95, had surgery on hip twenty years ago due to osteoarthritis. Woman from group II aged 91 was operated nine years ago due to knee osteoarthritis. Both long-livers have tried non-surgical treatments for several years, and they aren't enough to cope with the pain, swelling, stiffness, and other symptoms of $\mathrm{OA}$ and the doctor recommended them to make an operation.

During this period, long-livers with osteoarthritis diagnosed in the Genetic Laboratory of the State Medical University "Ivano-Frankivsk National Medical University", Ukraine, with various complaints and clinical manifestations.

Table 1: Age features of 369 longlivers from Precarpathian region (West Ukraine) for 1998-2014 yy.

\begin{tabular}{|c|c|c|c|c|c|c|c|c|c|c|c|c|}
\hline \multirow{3}{*}{$\begin{array}{l}\text { Age, } \\
\text { ears }\end{array}$} & \multicolumn{4}{|c|}{$\begin{array}{c}\text { Group I }(n=146) \\
\text { HD+OA }\end{array}$} & \multicolumn{4}{|c|}{$\begin{array}{c}\text { Group II }(n=93) \\
\text { only OA }\end{array}$} & \multicolumn{4}{|c|}{ Control $(n=130)$} \\
\hline & \multicolumn{2}{|c|}{ men } & \multicolumn{2}{|c|}{ women } & \multicolumn{2}{|c|}{ men } & \multicolumn{2}{|c|}{ women } & \multicolumn{2}{|c|}{ men } & \multicolumn{2}{|c|}{ women } \\
\hline & $\mathrm{n}$ & $\%$ & $\mathbf{n}$ & $\%$ & $\mathbf{n}$ & $\%$ & $\mathbf{n}$ & $\%$ & $\mathbf{n}$ & $\%$ & $\mathbf{n}$ & $\%$ \\
\hline $90-95$ & 39 & 75,0 & 69 & 73,4 & 24 & 80,0 & 45 & 71,4 & 41 & 95,3 & 80 & 92,0 \\
\hline$>95$ & $12^{\star}$ & 23,1 & $23^{\star}$ & 24,5 & $5^{\star}$ & 16,7 & $18^{*}$ & 28,6 & 2 & 4,7 & 7 & 8,0 \\
\hline$>100$ & 1 & 1,9 & 2 & 2,1 & 1 & 3,3 & - & - & - & - & - & - \\
\hline All & 52 & 100,0 & 94 & 100 & 30 & 100,0 & 63 & 100,0 & 43 & 100,0 & 87 & 100,0 \\
\hline
\end{tabular}

Note. *- the probability of differences with the indicators of a control group $(p<0,05)$

HD- hypertension disease, OA - osteoarthritis 
To study the peculiarities of karyotype in diseases with hypertension and $\mathrm{OA}$, a sample of 188 long- livers (76 men and 112 women) was created taking into account their desire and health at the time of blood collection. In long-livers patients with $\mathrm{OA}$, the differences from the frequency of chromosomal aberrations in persons of the control were not significant $(p>0,05)$ among men $(2.57 \pm 0.24)$ and among women $(2,33 \pm 0,29)$, respectively (Table 2$)$.

As can be seen from the data in table 2, there is a tendency for a higher frequency of chromosomal aberrations in male long-livers and tere are significant difference among control $(\mathrm{p}<0,05)$. In women of both groups, no significant difference was found in comparison with control $(\mathrm{p}>0,05)$.

The number of disorders of the hereditary apparatus at the chromosomal level was more often recorded in comorbid conditions, both in men and in women but there was no significant difference among control $(p>0,05)$.

A natural continuation of the study of adaptive possibilities and immunogenetic status of the organism was the study of association of acrocentric chromosomes. It has been established that the average number of associations of acrocentric chromosomes (Table 3) in long- livers patients with hypertension and OA prevailed in the control group $(\mathrm{p}<0,05)$.

As can be seen from the data in table 3, the total frequency of AAC cells was not significantly different in the various groups of long-livers, although it was at the highest with comorbidity. The number of chromosomes associated in a single cell was significantly higher $(\mathrm{p}<0,05)$ in both groups compared to control.

The average amount of AAC in a single cell in long-term residents with a combination of osteoarthritis and hypertension was 1.75 times higher $(\mathrm{p}<0.05)$ compared with those in healthy subjects. It was interesting that the average number of AAC in one cell was almost identical in the case of hypertension or OA, and did not differ significantly from that of healthy long-livers.

All investigated long-livers often found deletions. Their number prevailed in people with comorbid pathology. At the same time, there were more gaps in such long-livers, than in healthy subjects. With a true gap between the fragment and the chromosome there was no connection, one of the fragments on the metaphase plate looked displaced.

To investigate the distribution of associations of acrocentric chromosomes between different chromosomes in long-livers individuals, a statistical analysis was used (Table 4). Between 13-15, 14-22 and 21-22 chromosomes of the association in the first study group compared to the control $(\mathrm{p}<0.05)$.

Table 2: The frequency of chromosomal aberrations in long-livers from Precarpathian region (West Ukraine) depending on gender, $\mathrm{M} \pm \mathrm{m}$.

\begin{tabular}{|c|c|c|}
\hline \multirow{2}{*}{ Group } & \multicolumn{2}{|c|}{ Frequency of chromosomal aberrations } \\
\hline & men $(n=76)$ & women $(n=112)$ \\
\hline Group I $(n=83) \mathrm{HD}+\mathrm{OA}$ & $3,12 \pm 0,26^{*}$ & $2,91 \pm 0,37$ \\
\hline Group II $(n=49)$ only OA & $2,57 \pm 0,24$ & $2,33 \pm 0,29$ \\
\hline Control $(n=56)$ & $2,31 \pm 0,31$ & $2,03 \pm 0,62$ \\
\hline
\end{tabular}

Table 3: Frequency of associations of acrocentric chromosomes (AAC) in lymphocytes of peripheral blood of longlivers from Precarpathian region (West Ukraine), $\mathrm{M} \pm \mathrm{m}$.

\begin{tabular}{|c|c|c|c|}
\hline Group & $\begin{array}{l}\text { The frequency of cells with } \\
\text { AAC, } \%\end{array}$ & $\begin{array}{c}\text { The average number of AAC } \\
\text { in a single cell, } \%\end{array}$ & $\begin{array}{c}\text { The number of } \\
\text { chromosomes associated in } \\
\text { a single cell, \% }\end{array}$ \\
\hline Group I $(n=83) \mathrm{HD}+\mathrm{OA}$ & $93,68 \pm 0,27$ & $3,24 \pm 0,41 *$ & $4,1 \pm 0,22 *$ \\
\hline Group II $(n=49)$ only OA & $89,23 \pm 0,44$ & $2,09 \pm 0,31$ & $3,9 \pm 0,42 *$ \\
\hline Control $(n=56)$ & $82,83 \pm 0,61$ & $1,85 \pm 0,54$ & $2,5 \pm 0,14$ \\
\hline
\end{tabular}


Table 4: Associations between groups I (hypertension and osteoarthritis) of acrocentric chromosomes in long- livers compared with control.

\begin{tabular}{|c|c|c|c|c|}
\hline Combination type & Actual number & Expected number & $x^{2}$ & $\mathbf{P}$ \\
\hline $13-13$ & 21 & 27,51 & 3,33 & $>0,05$ \\
\hline $13-14$ & 108 & 106,47 & 0,03 & $>0,05$ \\
\hline $13-15$ & 111 & 105,27 & 0,70 & $<0,05$ \\
\hline $14-14$ & 32 & 33,50 & 0,08 & $>0,05$ \\
\hline $14-15$ & 150 & 150,13 & 0,00 & $>0,90$ \\
\hline $15-15$ & 20 & 20,93 & 0,02 & $>0,50$ \\
\hline $13-21$ & 150 & 155,51 & 0,45 & $>0,05$ \\
\hline $13-22$ & 172 & 177,05 & 0,33 & $>0,05$ \\
\hline $14-21$ & 141 & 147,74 & 0,73 & $>0,05$ \\
\hline $14-22$ & 100 & 117,83 & 6,90 & $<0,01$ \\
\hline $15-21$ & 110 & 116,64 & 0,84 & $>0,05$ \\
\hline $15-22$ & 80 & 91,51 & 3,52 & $>0,05$ \\
\hline $21-21$ & 56 & 52,06 & 0,59 & $>0,05$ \\
\hline $21-22$ & 181 & 132,19 & 48,27 & $<0,01$ \\
\hline $22-22$ & 37 & 35,89 & 0,03 & $>0,05$ \\
\hline
\end{tabular}

A greater number of cytogenetic disorders (predominance of chromosomal aberrations, AAC) in lymphocytes of long-lived peripheral blood with diseases of hypertension and $\mathrm{OA}$ have been established compared to those in long-livers without $\mathrm{HD}$ and $\mathrm{OA}$.

\section{Conclusion}

We evaluated 239 long-livers with on osteoarthritis and 130 longlivers without this pathology aged 90-102 years from Precarpathian region (West Ukraine) who were diagnosed and followed-up at the underwent karyotyping over a period of 16 years.

Although no significant difference was found with regard to the age of the groups ( $p>0.05$ ) under investigation, however, the greatest age at the time of examination was in patients with $\mathrm{OA}$ and hypertension compared with the control group. This explained by the fact that patients of group I had health problems and more often turned to doctors than longlivers without any complaints.

Cytogenetic characteristics of the long-livers with on osteoarthritis showed that most there is a tendency for a higher frequency of chromosomal aberrations in male long-livers and there are significant difference among control $(\mathrm{p}<0,05)$.

The number of chromosomes associated in a single cell was significantly higher $(p<0,05)$ in both groups compared to control.

\section{References}

1. Briggs AM, Page CJ, Shaw BR, Bendrups A, Philip K, et al. A Model of Care for Osteoarthritis of the Hip and Knee: Development of a System-Wide Plan for the Health Sector in Victoria, Australia. Healthc Policy. 2018; 14: 47-58. Ref.: https://tinyurl.com/y5q8w7jg

2. Cross M, Smith E, Hoy D, Nolte S, Ackerman I, et al. The global burden of hip and knee osteoarthritis: estimates from the global burden of disease 2010 study. Ann Rheum Dis. 2014; 73: 1323-1330. Ref.: https://tinyurl.com/y2zy4fer

3. Frolov AK, Artsimovich NG, Sokhin AA. Immunocytogenetics. Medicine. 1993; 240.

4. Guzhevsky IV, Gerasimenkov SI, Magomedov AA, Panchenko LM. On the question of the local treatment of some types of primary gonarthrosis in adults [Article in Ukrainian] / Ukr J Clinical and Laboratory Medicine. 2009; 4: 70-74.

5. Huang D, Liu YQ, Liang LS, Lin XW, Song T, et al. The Diagnosis and Therapy of Degenerative Knee Joint Disease: Expert Consensus from the Chinese Pain Medicine Panel. Pain Res Manag. 2018; 2018: 2010129. Ref.: https://tinyurl.com/yxpwjan4

6. ISCN 2013. An International System for Human Cytogenetic Nomenclature (2013)/ LG Shaffer, J McGowan-Jordan, M Schmid // Karger.-2013; 137. Ref.: https://tinyurl.com/yy2766p2 
7. Magnusson K, Turkiewicz A, Englund M. Nature vs nurture in knee osteoarthritis - the importance of age, sex and body mass index. Osteoarthritis Cartilage. 2019; 27: 586-592. Ref.: https://tinyurl.com/yx9x7lmm

8. Moorhead PS, Nowell PC, Mellman WJ, Battips DM, Hungerford DA. Chromosome preparations of leukocytes cultured from human peripheral blood. Exp Cell Res. 1960; 20: 613-616. Ref.: https://tinyurl.com/yyz2dcr8

9. Population of Ivano-Frankivsk. Ref.: https://tinyurl.com/y6bk4lyz

10. Postler A, Ramos AL, Goronzy J, Günther KP, Lange T, et al. Prevalence and treatment of hip and knee osteoarthritis in people aged 60 years or older in Germany: an analysis based on health insurance claims data. Clin Interv Aging. 2018; 13: 2339-2349. Ref.: https://tinyurl.com/y5gwwhgr

11. Povoroznyuk VV. Neuropathic pain component in patients of various age with knee osteoarthritis. 9th Congress of the European Pain Federation EFIC. Vienna, 2015: 396-397. Ref.: https://tinyurl.com/yyvrecza

12. Seabright M. A rapid banding technique for human chromosomes. Lancet. 1971; 2: 971-972. Ref.: https://tinyurl.com/y66n7cn4

13. Meiner SE, Yeager JJ. Gerontologic Nursing - E-Book. Arthritis-Related Statistics: Prevalence of Arthritis in the United States. Centers for Disease Control and Prevention, US Department of Health and Human Services. 9 November 2016. Archived from the original on 29 December 2016. Ref.: https://tinyurl.com/y45tgk52

14. Tachmazidou I, Hatzikotoulas K, Southam L, Esparza-Gordillo J, Haberland V, et al. Identification of new therapeutic targets for osteoarthritis through genome-wide analyses of UK Biobank data. Nat Genet. 2019; 51: 230-236. Ref.: https://tinyurl.com/y6z57ypj

15. Timmermans EJ, de Koning EJ, van Schoor NM, van der Pas S, Denkinger MD, et al. Within-person pain variability and physical activity in older adults with osteoarthritis from six European countries. BMC Musculoskelet Disord. 2019; 20: 12. Ref.: https://tinyurl.com/y3odr3cv

16. Thorlund JB, Turkiewicz A, Prieto-Alhambra D, Englund M. Opioid use in knee or hip osteoarthritis: a region-wide population-based cohort study. Osteoarthritis Cartilage. 2019; pii: S1063-4584(19)300305. Ref.: https://tinyurl.com/y3te5dtk

17. Wang $X$, Jin $X$, Han W, Cao Y, Halliday A, et al. Cross-sectional and longitudinal associations between knee joint effusion synovitis and knee pain in older adults. J Rheumatol. 2016; 43: 121-130. Ref.: https://tinyurl.com/y6e5mqdr

18. White DK, Lee J, Song J, Chang RW, Dunlop D. Potential functional benefit from light intensity physical activity in knee osteoarthritis. Am J Prev Med. 2017; 53: 689-696. Ref.: https://tinyurl.com/yypnvdb9

19. Zengini E, Hatzikotoulas K, Tachmazidou I, Steinberg J, Hartwig FP, et al. Genome-wide analyses using UK Biobank data provide insights into the genetic architecture of osteoarthritis. Nat Genet. 2018; 50: 549-558. Ref.: https://tinyurl.com/y5vermzs

20. Zerova-Lyubimova TE, Gorovenko NG. Cytogenetic methods for the study of human chromosomes. Guidelines. [In Ukrainian] - Kyiv; 2003; 24. 